\title{
The Evaluation of Body Composition: A Useful Tool for Clinical Practice
}

\author{
Ronan Thibault ${ }^{\mathrm{a}}$ Claude Pichard $^{\mathrm{b}}$ \\ ${ }^{a}$ Centre de Recherche en Nutrition Humaine Auvergne, UMR 1019 Nutrition Humaine, INRA, Clermont Université, \\ Service de Nutrition Clinique, CHU de Clermont-Ferrand, Clermont-Ferrand, France; b Nutrition Unit, Geneva \\ University Hospital, Geneva, Switzerland
}

\section{Key Words}

Fat-free mass · Fat mass • Undernutrition • Bioelectrical

impedance analysis $\cdot$ Sarcopenic obesity $\cdot$ Drug toxicity

\begin{abstract}
Undernutrition is insufficiently detected in in- and outpatients, and this is likely to worsen during the next decades. The increased prevalence of obesity together with chronic illnesses associated with fat-free mass (FFM) loss will result in an increased prevalence of sarcopenic obesity. In patients with sarcopenic obesity, weight loss and the body mass index lack accuracy to detect FFM loss. FFM loss is related to increasing mortality, worse clinical outcomes, and impaired quality of life. In sarcopenic obesity and chronic diseases, body composition measurement with dual-energy X-ray absorptiometry, bioelectrical impedance analysis, or computerized tomography quantifies the loss of FFM. It allows tailored nutritional support and disease-specific therapy and reduces the risk of drug toxicity. Body composition evaluation should be integrated into routine clinical practice for the initial assessment and sequential follow-up of nutritional status. It could allow objective, systematic, and early screening of undernutrition and promote the rational and early initiation of optimal nutritional support, thereby contributing to reducing malnutrition-induced morbidity, mortality, worsening of the quality of life, and global health care costs.

Copyright $\odot 2011$ S. Karger AG, Basel
\end{abstract}

\section{KARGER}

Fax +4161306 1234 E-Mail karger@karger.ch www.karger.com

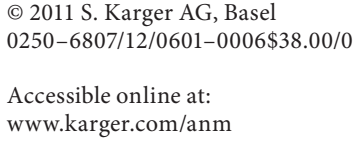

\section{Introduction}

Chronic undernutrition is characterized by a progressive reduction of the fat-free mass (FFM) and fat mass (FM) which has deleterious consequences on health. Undernutrition is insufficiently screened and treated in hospitalized or at-risk patients despite its high prevalence and negative impact on mortality, morbidity, length of stay (LOS), quality of life, and costs [1-4]. The risk of underestimating hospital undernutrition is likely to worsen in the next decades because of the increasing prevalence of overweight, obesity, and chronic diseases and the increased number of elderly subjects. These clinical conditions are associated with FFM loss (sarcopenia). Therefore, an increased number of patients with FFM loss and sarcopenic obesity will be seen in the future.

Sarcopenic obesity is associated with decreased survival and increased therapy toxicity in cancer patients [5-10], whereas FFM loss is related to decreased survival, a negative clinical outcome, increased health care costs [2], and impaired overall health, functional capacities, and quality of life [4-11]. Therefore, the detection and treatment of FFM loss is a major issue of public health and health costs [12].

Weight loss and the body mass index (BMI) lack sensitivity to detect FFM loss [13]. In this review, we support the systematic assessment of FFM with a method of body composition evaluation in order to improve the detec-

Dr. Ronan Thibault

Centre de Recherche en Nutrition Humaine Auvergne

58, rue Montalembert, BP 321

FR-63009 Clermont-Ferrand Cedex 1 (France)

Tel. +334736082 70, E-Mail rthibault@chu-clermontferrand.fr 
Fig. 1. Conceptualization of the expected impact of early use of body composition for the screening of fat-free loss and undernutrition in sarcopenic overweight and obese subjects. An increased prevalence of overweight and obesity is observed in all Western and emerging countries. Simultaneously, the ageing of the population, the reduction of the level of physical activity, and the higher prevalence of chronic diseases and cancer increased the number of patients with or at risk of FFM impairment, i.e. sarcopenia. Thus, more patients are presenting with 'sarcopenic overweight or obesity'. In these patients, evaluation of nutritional status using anthropometric methods, i.e. weight loss and calculation of BMI, is not sensitive enough to detect FFM impairment. As a result, undernutrition is not detected, worsens, and negatively impacts morbidity, mortality, LOS, length of recovery, quality of life, and health care costs. On the contrary, in patients with 'sarcopenic overweight or obesity', early screening of undernutrition with a dedicated method of body composition evaluation would allow early initiation of nutritional support and, in turn, improvements of nutritional status and clinical outcome.

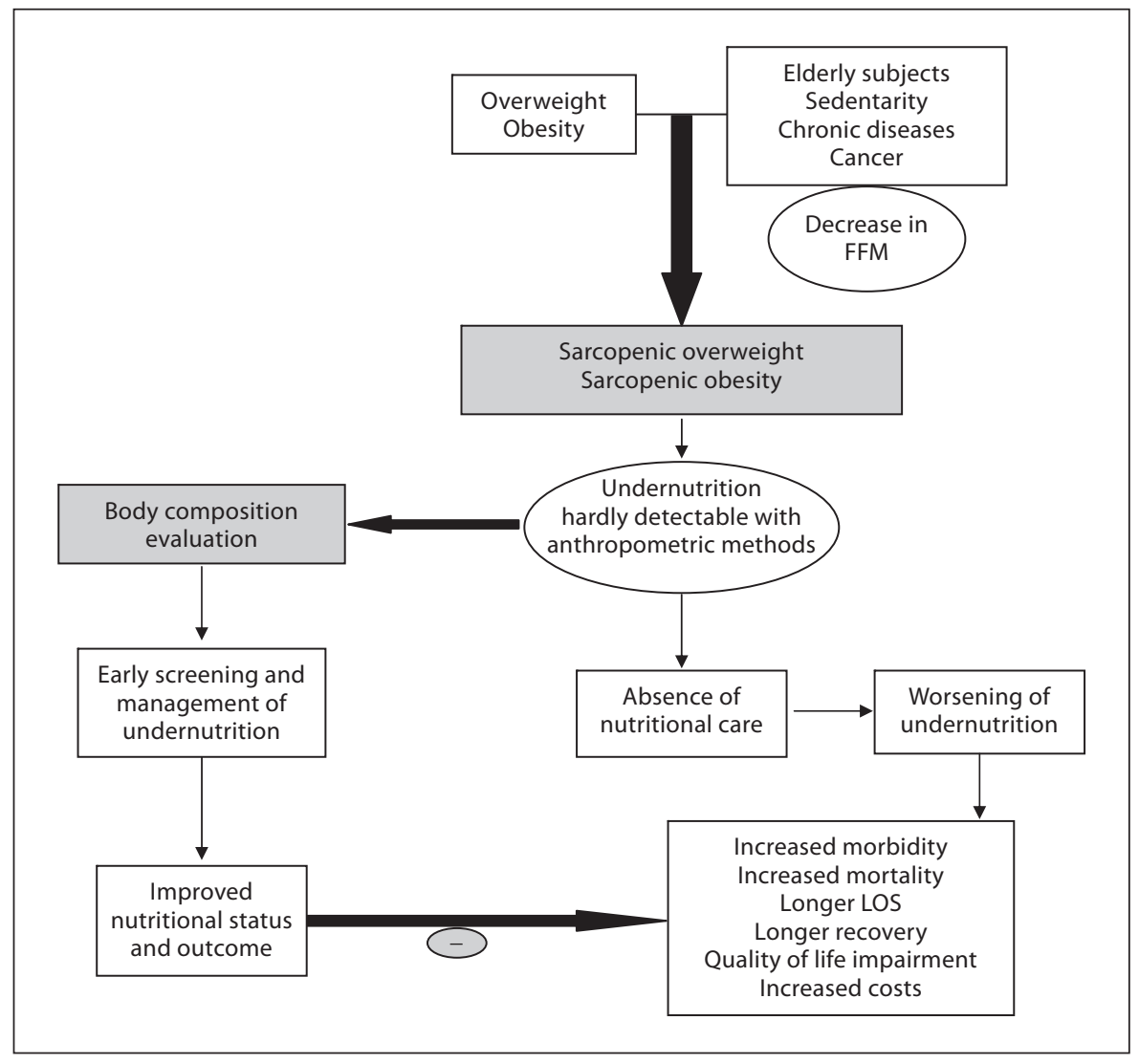

tion, management, and follow-up of undernutrition. Such an approach should in turn reduce the clinical and functional consequences of diseases in the setting of a costeffective medico-economic approach (fig. 1). We discuss the main applications of body composition evaluation in clinical practice (fig. 2).

\section{Rationale for a New Strategy for the Screening of Undernutrition}

\section{Screening of Undernutrition Is Insufficient}

Academic societies encourage systematic screening of undernutrition at hospital admission and during the hospital stay [14]. The detection of undernutrition is generally based on measurements of weight and height, calculations of BMI, and the percentage of weight loss. Nevertheless, screening of undernutrition is infrequent in hospitalized or nutritionally at-risk ambulatory patients. For example, in France, surveys performed by the French Health Authority [15] indicate that: (i) weight alone, (ii) weight with $\mathrm{BMI}$ or percentage of weight loss, and (iii) weight, BMI, and percentage of weight loss are reported in only 55, 30, and $8 \%$ of the hospitalized patients' records, respectively. Several issues, which could be improved by specific educational programs, explain the lack of implementation of nutritional screening in hospitals (table 1). In addition, the accuracy of the clinical screening of undernutrition could be limited at hospital admission. Indeed, patients with undernutrition may have the same BMI as sex- and agematched healthy controls but a significantly decreased FFM hidden by an expansion of the FM and the total body water which can be measured by bioelectrical impedance analysis (BIA) [13]. This example illustrates that body composition evaluation allows a more accurate identification of FFM loss than body weight loss or BMI decrease. The lack of sensitivity and specificity of weight, BMI, and percentage of weight loss argue for the need for other methods to evaluate the nutritional status.

\section{Changes in Patients' Profiles}

In 2008, twelve and thirty percent of the worldwide adult population was obese or overweight; this is two times higher than in 1980 [16]. The prevalence of over- 


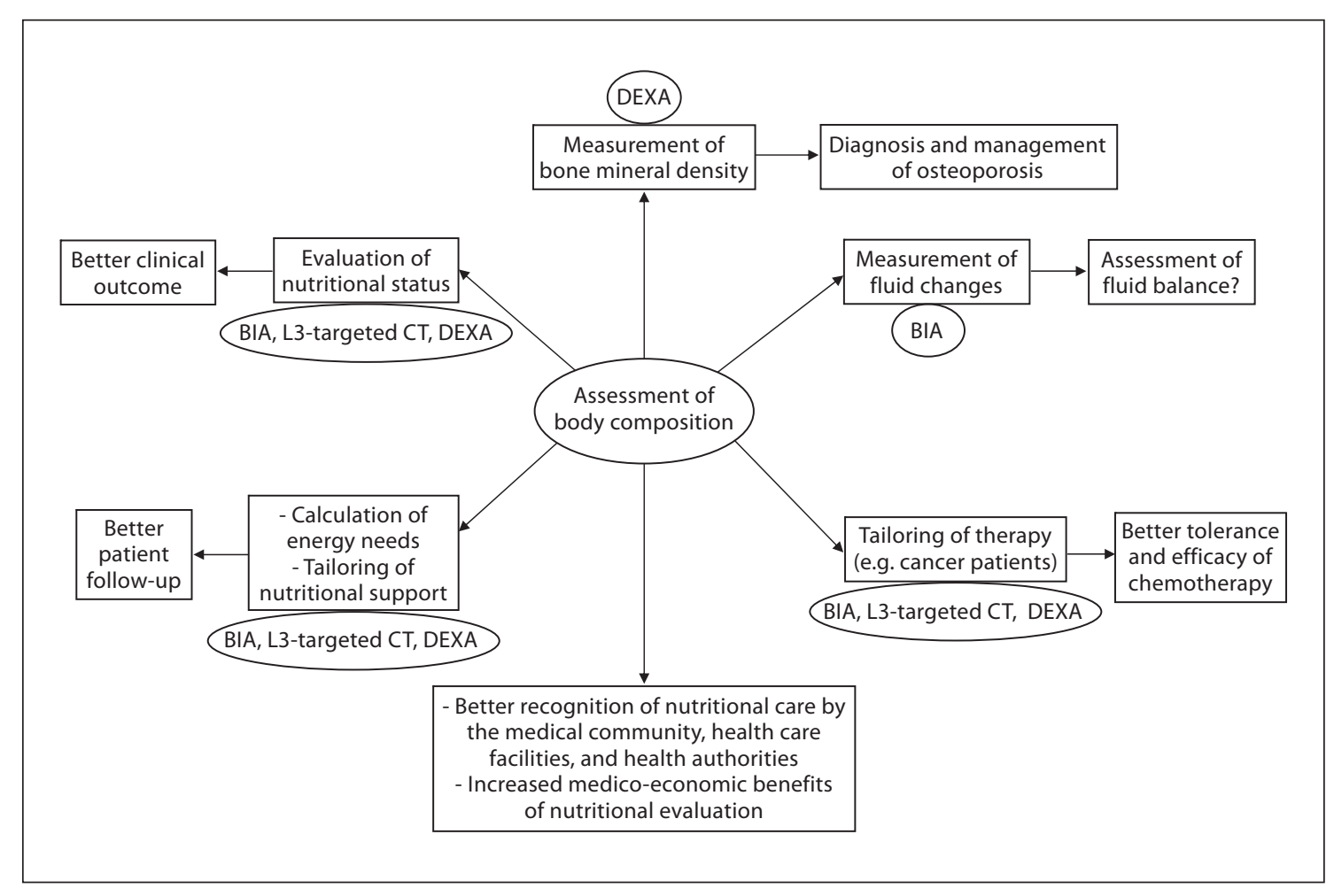

Fig. 2. Current and potential applications of body composition evaluation in clinical practice. The applications are indicated in the boxes, and the body composition methods that could be used for each application are indicated inside the circles. The most used application of body composition evaluation is the measurement of bone mineral density by DEXA for the diagnosis and management of osteoporosis. Although a low FFM is associated with worse clinical outcomes, FFM evaluation is not yet implemented enough in clinical practice. However, by allowing early detection of undernutrition, body composition evaluation could improve the clinical outcome. Body composition evaluation could also be used to follow up nutritional status, calculate energy needs, tailor nutritional support, and assess fluid changes during perioperative period and renal insufficiency. Recent evidence indicates that a low FFM is associated with a higher toxicity of some chemotherapy drugs in cancer patients. Thus, by allowing tailoring of the chemotherapy doses to the FFM in cancer patients, body composition evaluation should improve the tolerance and the efficacy of chemotherapy. BIA, L3-targeted CT, and DEXA could be used for the assessment of nutritional status, the calculation of energy needs, and the tailoring of nutritional support and therapy. Further studies are warranted to validate BIA as an accurate method for fluid balance measurement. By integrating body composition evaluation into the management of different clinical conditions, all of these potential applications would lead to a better recognition of nutritional care by the medical community, the health care facilities, and the health authorities, as well as to an increase in the medico-economic benefits of the nutritional evaluation. weight and obesity is also increasing in hospitalized patients. A 10-year comparative survey performed in a European hospital showed an increase in patients' BMI, together with a shorter LOS [17]. The BMI increase masks undernutrition and FFM loss at hospital admission. The increased prevalence of obesity in an ageing population has led to the recognition of a new nutritional entity: 'sarcopenic obesity' [18]. Sarcopenic obesity is characterized by increased FM and reduced FFM with a normal or high body weight. The emergence of the concept of sarcopenic obesity will increase the number of situations associated with a lack of sensitivity of the calculations of BMI and body weight change for the early detection of FFM loss. This supports a larger use of body composition evaluation for the assessment and follow-up of nutritional status in clinical practice (fig. 1).

\section{Body Composition Evaluation for the Assessment of Nutritional Status}

Body composition evaluation is a valuable technique to assess nutritional status. Firstly, it gives an evaluation of nutritional status through the assessment of FFM. Sec- 
Table 1. Main reasons for the lack of nutritional screening at hospitals

\begin{tabular}{|c|c|c|c|}
\hline Parameters & $\begin{array}{l}\text { Impossible measurement for medical } \\
\text { reasons }\end{array}$ & Difficult interpretation & Organizational reasons \\
\hline Weight & $\begin{array}{l}\text { Impossibility to stand up: mandatory } \\
\text { bedridden position, subject confined to bed, } \\
\text { impaired physical function. }\end{array}$ & $\begin{array}{l}\text { Overhydration } \\
\text { Dehydration } \\
\text { Miscalibrated weigh machine } \\
\text { Overweight and obesity }\end{array}$ & $\begin{array}{l}\text { Lack of time } \\
\text { Lack of knowledge of health carers, including physicians, } \\
\text { about the impact of undernutrition on clinical outcome. } \\
\text { Lack of manpower } \\
\text { Lack of weigh machines }\end{array}$ \\
\hline $\begin{array}{l}\text { Body mass } \\
\text { index }\end{array}$ & $\begin{array}{l}\text { Undeterminable height: mandatory } \\
\text { bedridden position, subject confined to bed, } \\
\text { impaired physical function. } \\
\text { Unknown height: memory dysfunction, } \\
\text { dementia, coma. }\end{array}$ & $\begin{array}{l}\text { Overhydration } \\
\text { Dehydration } \\
\text { Miscalibrated weigh machine } \\
\text { Overweight and obesity }\end{array}$ & $\begin{array}{l}\text { Lack of time } \\
\text { Lack of knowledge of health carers about the impact of } \\
\text { undernutrition on clinical outcome } \\
\text { Lack of manpower } \\
\text { Lack of height gauge }\end{array}$ \\
\hline $\begin{array}{l}\text { Percentage of } \\
\text { weight loss }\end{array}$ & $\begin{array}{l}\text { Undeterminable usual weight: unknown, } \\
\text { memory dysfunction, dementia, coma. }\end{array}$ & $\begin{array}{l}\text { Overhydration } \\
\text { Dehydration } \\
\text { Miscalibrated weigh machine } \\
\text { Overweight and obesity }\end{array}$ & $\begin{array}{l}\text { Lack of time } \\
\text { Lack of knowledge towards undernutrition } \\
\text { Lack of health carers }\end{array}$ \\
\hline
\end{tabular}

Table 2. Mean values of body composition compartments (adapted from Pichard and Kyle [19] and Wang et al. [20])

\begin{tabular}{|c|c|c|c|c|}
\hline $\begin{array}{l}\text { Whole-body } \\
\text { compartments }\end{array}$ & Specific compartments & $\begin{array}{l}\text { Compartment levels, } \\
\text { according to Wang et al. [20] }\end{array}$ & $\begin{array}{l}\text { Percentage of } \\
\text { total body weight }\end{array}$ & $\begin{array}{l}\text { Absolute values in a } \\
\text { 70-kg human subject, } \mathrm{kg}\end{array}$ \\
\hline FFM & Body proteins & molecular & 13 & 9 \\
\hline \multirow[t]{6}{*}{ (including TBW) } & ICW & cellular & 36 & 25 \\
\hline & $\mathrm{ECW}$ & cellular & 24 & 17 \\
\hline & Bone tissue & tissular & 7 & 5 \\
\hline & $\mathrm{ACM}=$ body proteins $+\mathrm{ICW}$ & cellular & 49 & 34 \\
\hline & $\mathrm{TBW}=\mathrm{ICW}+\mathrm{ECW}$ & molecular & 60 & 42 \\
\hline & $\begin{array}{l}\text { Total FFM (= body proteins } \\
+ \text { ICW + ECW + bone tissue })\end{array}$ & whole-body & 80 & 56 \\
\hline FM & - & & 20 & 14 \\
\hline
\end{tabular}

$\mathrm{ACM}=$ Active cell mass; ECW = extracellular water; ICW = intracellular water; TBW = total body water.

ondly, by measuring FFM and phase angle with BIA, it allows evaluation of the disease prognosis and outcome.

\section{Body Composition Techniques for FFM Measurement}

Body composition evaluation allows measurement of the major body compartments: FFM (including bone mineral tissue), FM, and total body water. Table 2 shows indicative values of the body composition of a healthy subject weighing $70 \mathrm{~kg}$. In several clinical situations, i.e. hospital admission, chronic obstructive pulmonary disease (COPD) [21-23], dialysis [24-26], chronic heart failure [27], amyotrophic lateral sclerosis [28], cancer [5, 29], liver transplantation [30], nursing home residence [31], and Alzheimer's disease [32], changes in body compart- ments are detected with the techniques of body composition evaluation. At hospital admission, body composition evaluation could be used for the detection of FFM loss and undernutrition. Indeed, FFM and the FFM index (FFMI) [FFM (kg)/height $\left(\mathrm{m}^{2}\right)$ ] measured by BIA are significantly lower in hospitalized patients $(n=995)$ than in age-, height-, and sex-matched controls $(n=995)$ [3]. Conversely, clinical tools of nutritional status assessment, such as BMI, subjective global assessment, or mini-nutritional assessment, are not accurate enough to estimate FFM loss and nutritional status [30, 32-34]. In 441 patients with non-small cell lung cancer, FFM loss determined by computerized tomography (CT) was observed in each BMI category [7], and in young adults with all 
types of cancer, an increase in FM together with a decrease in FFM were reported [29]. These findings reveal the lack of sensitivity of BMI to detect FFM loss. Moreover, the FFMI is a more sensitive determinant of LOS than a weight loss over $10 \%$ or a BMI below 20 [3]. In COPD, the assessment of FFM by BIA is a more sensitive method to detect undernutrition than anthropometry $[33,35]$. BIA is also more accurate at assessing nutritional status in children with severe neurologic impairment than the measurement of skinfold thickness [36].

Body Composition for the Evaluation of Prognosis and Clinical Outcome

FFM loss is correlated with survival in different clinical settings [5, 21-28, 37]. In patients with amyotrophic lateral sclerosis, an FM increase, but not an FFM increase, measured by BIA, was correlated with survival during the course of the disease [28]. The relation between body composition and mortality has not yet been demonstrated in the intensive care unit. The relation between body composition and mortality has been demonstrated with anthropometric methods, BIA, and CT. Measurement of the mid-arm muscle circumference is an easy tool to diagnose sarcopenia [38]. The mid-arm muscle circumference has been shown to be correlated with survival in patients with cirrhosis [39, 40], HIV infection [41], and COPD in a stronger way than BMI [42]. The relation between FFM loss and mortality has been extensively shown with BIA [21-28, 31, 37], which is the most used method. Recently, very interesting data suggest that $\mathrm{CT}$ could evaluate the disease prognosis in relation to muscle wasting. In obese cancer patients, sarcopenia as assessed by CT measurement of the total skeletal muscle cross-sectional area is an independent predictor of the survival of patients with bronchopulmonary $[5,7]$, gastrointestinal [5], and pancreatic cancers [6]. FFM assessed by measurement of the mid-thigh muscle crosssectional area by CT is also predictive of mortality in COPD patients with severe chronic respiratory insufficiency [43]. In addition to mortality, a low FFMI at hospital admission is significantly associated with an increased LOS [3, 44]. A bicentric controlled population study performed in 1,717 hospitalized patients indicates that both loss of FFM and excess of FM negatively affect the LOS [44]. Patients with sarcopenic obesity are most at risk of increased LOS. This study also found that excess FM reduces the sensitivity of BMI to detect nutritional depletion [44]. Together with the observation that the BMI of hospitalized patients has increased during the last decade [17], these findings suggest that FFM and
FFMI measurement should be used to evaluate nutritional status in hospitalized patients.

BIA measures the phase angle [45]. A low phase angle is related to survival in oncology [46-50], HIV infection/ AIDS [51], amyotrophic lateral sclerosis [52], geriatrics [53], peritoneal dialysis [54], and cirrhosis [55]. The phase angle threshold associated with reduced survival is variable: less than 2.5 degrees in amyotrophic lateral sclerosis patients [52], 3.5 degrees in geriatric patients [53], from less than 1.65 to 5.6 degrees in oncology patients [47-50], and 5.4 degrees in cirrhotic patients [55]. The phase angle is also associated with the severity of lymphopenia in AIDS [56], and with the risk of postoperative complications among gastrointestinal surgical patients [57]. The relation of phase angle with prognosis and disease severity reinforces the interest in using BIA for the clinical management of patients with chronic diseases at high risk of undernutrition and FFM loss.

In summary, FFM loss or a low phase angle is related to mortality in patients with chronic diseases, cancer (including obesity cancer patients), and elderly patients in long-stay facilities. A low FFM and an increased FM are associated with an increased LOS in adult hospitalized patients. The relation between FFM loss and clinical outcome is clearly shown in patients with sarcopenic obesity. In these patients, as the sensitivity of BMI for detecting FFM loss is strongly reduced, body composition evaluation appears to be the method of choice to detect undernutrition in routine practice. Overall, the association between body composition, phase angle, and clinical outcome reinforces the pertinence of using a body composition evaluation in clinical practice.

\section{Which Technique of Body Composition Evaluation}

Should Be Used for the Assessment of Nutritional

Status?

Numerous methods of body composition evaluation have been developed: anthropometry, including the 4-skinfold method [58], hydrodensitometry [58], in vivo neutron activation analysis [59], anthropogammametry from total body potassium-40 [60], nuclear magnetic resonance [61], dual-energy X-ray absorptiometry (DEXA) $[62,63]$, BIA $[45,64-66]$, and more recently CT $[7,43,67]$. DEXA, BIA, and CT appear to be the most convenient methods for clinical practice (fig. 2), while the other methods are reserved for scientific use.

Compared with other techniques of body composition evaluation, the lack of reproducibility and sensitivity of the 4-skinfold method limits its use for the accurate measurement of body composition in clinical practice [33, 
34]. However, in patients with cirrhosis [39, 40], COPD [34], and HIV infection [41], measurement of the midarm muscle circumference could be used to assess sarcopenia and disease-related prognosis. DEXA allows noninvasive direct measurement of the three major components of body composition. The measurement of bone mineral tissue by DEXA is used in clinical practice for the diagnosis and follow-up of osteoporosis. As the clinical conditions complicated by osteoporosis are often associated with undernutrition, i.e. elderly women, patients with organ insufficiencies, COPD [68], inflammatory bowel diseases, and celiac disease, DEXA could be of the utmost interest for the follow-up of both osteoporosis and nutritional status. However, the combined evaluation of bone mineral density and nutritional status is difficult to implement in clinical practice because the reduced accessibility of DEXA makes it impossible to be performed in all nutritionally at-risk or malnourished patients. The principles and clinical utilization of BIA have been largely described in two ESPEN position papers $[45,66]$. BIA is based on the capacity of hydrated tissues to conduct electrical energy. The measurement of total body impedance allows estimation of total body water by assuming that total body water is constant. From total body water, validated equations allow the calculation of FFM and FM [69], which are interpreted according to reference values [70]. BIA is the only technique which allows calculation of the phase angle, which is correlated with the prognosis of various diseases. BIA equations are valid for: COPD [65]; AIDS wasting [71]; heart, lung, and liver transplantation [72]; anorexia nervosa [73] patients, and elderly subjects [74]. However, no BIA-specific equations have been validated in patients with extreme BMI (less than 17 and higher than 33.8) and dehydration or fluid overload $[45,66]$. Nevertheless, because of its simplicity, low cost, quickness of use at bedside, and high interoperator reproducibility, BIA appears to be the technique of choice for the systematic and repeated evaluation of FFM in clinical practice, particularly at hospital admission and in chronic diseases. Finally, through written and objective reports, the wider use of BIA should allow improvement of the traceability of nutritional evaluation and an increase in the recognition of nutritional care by the health authorities. Recently, several data have suggested that CT images targeted on the 3rd lumbar vertebra (L3) could strongly predict whole-body fat and FFM in cancer patients, as compared with DEXA [7, 67]. Interestingly, the evaluation of body composition by CT presents great practical significance due to its routine use in patient diagnosis, staging, and follow-up. L3-targeted CT images evaluate FFM by measuring the muscle cross-sectional area from L3 to the iliac crest by use of Hounsfield unit (HU) thresholds $(-29$ to +150$)[5,7]$. The muscles included in the calculation of the muscle cross-sectional area are psoas, paraspinal muscles (erector spinae, quadratus lumborum), and abdominal wall muscles (transversus abdominis, external and internal obliques, rectus abdominis) [6]. CT also provided detail on specific muscles, adipose tissues, and organs not provided by DEXA or BIA. L3-targeted CT images could be theoretically performed solely, since they result in X-ray exposition similar to that of a chest radiography.

In summary, DEXA, BIA, and L3-targeted CT images could all measure body composition accurately. The technique selection will depend on the clinical context, hardware, and knowledge availability. Body composition evaluation by DEXA should be performed in patients having a routine assessment of bone mineral density. Also, analysis of L3-targeted CT is the method of choice for body composition evaluation in cancer patients. Body composition evaluation should also be done for every abdominal CT performed in patients who are nutritionally at risk or undernourished. Because of its simplicity of use, BIA could be widely implemented as a method of body composition evaluation and follow-up in a great number of hospitalized and ambulatory patients. Future research will aim to determine whether a routine evaluation of body composition would allow early detection of the increased FFM catabolism related to critical illness [75].

\section{Body Composition Evaluation for the Calculation of Energy Needs}

The evaluation of FFM could be used for the calculation of energy needs, thus allowing the optimization of nutritional intakes according to nutritional needs. This could be of great interest in specific situations, such as severe neurologic disability, overweight, and obesity. In 61 children with severe neurologic impairment and intellectual disability, an equation integrating body composition had good agreement with the doubly labeled water method. It gave a better estimation of energy expenditure than did the Schofield predictive equation [36]. However, in 9 anorexia nervosa patients with a mean BMI of 13.7, prediction formulas of resting energy expenditure including FFM did not allow accurate prediction of the resting energy expenditure measured by indirect calorimetry [76]. In overweight or obese patients, the muscle catabolism in response to inflammation was the same as that observed 
in patients with normal BMI. Indeed, despite a higher $\mathrm{BMI}$, the FFM of overweight or obese individuals is similar (or slightly increased) to that of patients with normal BMI. Thus, the use of actual weight for the assessment of the energy needs of obese patients would result in overfeeding and its related complications. Therefore, the experts recommend the use of indirect calorimetry or calculation of the energy needs of overweight or obese patients as follows: $15 \mathrm{kcal} / \mathrm{kg}$ actual weight/day or $20-25$ $\mathrm{kcal} / \mathrm{kg}$ ideal weight/day [77, 78], although these predictive formulas could be inaccurate in some clinical conditions [79]. In a US prospective study conducted in 33 ICU medical and surgical ventilated ICU patients, daily measurement of the active cell mass (table 2) by BIA was used to assess the adequacy between energy/protein intakes and needs. In that study, nutritional support with $30 \mathrm{kcal} /$ $\mathrm{kg}$ actual body weight/day energy and $1.5 \mathrm{~g} / \mathrm{kg} /$ day protein allowed stabilization of the active cell mass [75]. Thus, follow-up of FFM by BIA could help optimize nutritional intakes when indirect calorimetry cannot be performed.

In summary, the measurement of FFM should help adjust the calculation of energy needs (expressed as $\mathrm{kcal} / \mathrm{kg}$ FFM) and optimize nutritional support in critical cases other than anorexia nervosa.

\section{Body Composition Evaluation for the Follow-Up and Tailoring of Nutritional Support}

Body composition evaluation allows a qualitative assessment of body weight variations. The evaluation of body composition may help to document the efficiency of nutritional support during a patient's follow-up of numerous clinical conditions, such as surgery [59], anorexia nervosa $[76,80]$, hematopoietic stem cell transplantation [81], COPD [82], ICU [83], lung transplantation [84], ulcerative colitis [59], Crohn's disease [85], cancer [86, 87], HIV/AIDS [88], and acute stroke in elderly patients [89]. Body composition evaluation could be used for the follow-up of healthy elderly subjects [90]. Body composition evaluation allows characterization of the increase in body mass in terms of FFM and FM [81, 91]. After hematopoietic stem cell transplantation, the increase in $\mathrm{BMI}$ is the result of the increase in FM, but not of the increase in FFM [81]. Also, during recovery after an acute illness, weight gain 6 months after ICU discharge could be mostly related to an increase in FM (+7 kg) while FFM only increased by $2 \mathrm{~kg}$; DEXA and air displacement plethysmography were used to measure the FM and FFM [91]. These two examples suggest that body composition eval- uation could be helpful to decide the modification and/or the renewal of nutritional support. By identifying the patients gaining weight but reporting no or insufficient FFM, body composition evaluation could contribute to influencing the medical decision of continuing nutritional support that would have been stopped in the absence of body composition evaluation.

In summary, body composition evaluation is of the utmost interest for the follow-up of nutritional support and its impact on body compartments.

\section{Body Composition Evaluation for Tailoring Medical Treatments}

In clinical situations when weight and BMI do not reflect the FFM, the evaluation of body composition should be used to adapt drug doses to the FFM and/or FM absolute values in every patient. This point has been recently illustrated in oncology patients with sarcopenic obesity. FFM loss was determined by CT as described above. In cancer patients, some therapies could affect body composition by inducing muscle wasting [92]. In patients with advanced renal cell carcinoma [92], sorafenib induces a significant $8 \%$ loss of skeletal muscular mass at 12 months. In turn, muscle wasting in patients with BMI less than 25 was significantly associated with sorafenib toxicity in patients with metastatic renal cancer [8]. In metastatic breast cancer patients receiving capecitabine treatment, and in patients with colorectal cancer receiving 5-fluoro-uracile, using the convention of dosing per unit of body surface area, FFM loss was the determinant of chemotherapy toxicity $[9,10]$ and time to tumor progression [10]. In colorectal cancer patients administered 5-fluoro-uracil, low FFM is a significant predictor of toxicity only in female patients [9]. The variation in toxicity between women and men may be partially explained by the fact that FFM was lower in females. Indeed, FFM represents the distribution volume of most cytotoxic chemotherapy drugs. In 2,115 cancer patients, the individual variations in FFM could change by up to three times the distribution volume of the chemotherapy drug per body area unit [5]. Thus, administering the same doses of chemotherapy drugs to a patient with a low FFM compared to a patient with a normal FFM would increase the risk of chemotherapy toxicity [5]. These data suggest that FFM loss could have a direct impact on the clinical outcome of cancer patients. Decreasing chemotherapy doses in case of FFM loss could contribute to improving cancer patients' prognosis through the improvement of the toler- 
ance of chemotherapy. These findings justify the systematic evaluation of body composition in all cancer patients in order to detect FFM loss, tailor chemotherapy doses according to FFM values, and then improve the efficacytolerance and cost-efficiency ratios of the therapeutic strategies [93]. Body composition evaluation should also be used to tailor the doses of drugs which are calculated based on patients' weight, e.g. corticosteroids, immunosuppressors (infliximab, azathioprine or methotrexate), or sedatives (propofol).

In summary, measurement of FFM should be implemented in cancer patients treated with chemotherapy. Clinical studies are needed to demonstrate the importance of measuring body composition in patients treated with other medical treatments.

\section{Towards the Implementation of Body Composition Evaluation in Clinical Practice}

The implementation of body composition evaluation in routine care presents a challenge for the next decades. Indeed the concomitant increases in elderly subjects and patients with chronic diseases and cancer, and in the prevalence of overweight and obesity in the population, will increase the number of patients nutritionally at risk or undernourished, particularly those with sarcopenic obesity. Body composition evaluation should be used to improve the screening of undernutrition in hospitalized patients. The results of body composition should be based on the same principle as BMI calculation, towards the systematic normalization for body height of FFM (FFMI) and FM [FM $(\mathrm{kg}) /$ height $(\mathrm{m})^{2}=\mathrm{FM}$ index] [94]. The results could be expressed according to previously described percentiles of healthy subjects $[95,96]$. Body composition evaluation should be performed at the different stages of the disease, during the course of treatments and the rehabilitation phase. Such repeated evaluations of body composition could allow assessment of the nutritional status, adjusting the calculation of energy needs as kilocalories/kilogram FFM, following the efficacy of nutritional support, and tailoring drug and nutritional therapies. BIA, L3-targeted CT, and DEXA represent the techniques of choice to evaluate body composition in clinical practice (fig. 2). In the setting of cost-effective and pragmatic use, these three techniques should be alternatively chosen. In cancer, undernourished, and nutritionally at-risk patients, an abdominal CT should be completed by the analysis of L3-targeted images for the evaluation of body composition.

Body Composition in Practice
In other situations, BIA appears to be the simplest most reproducible and less expensive method, while DEXA, if feasible, remains the reference method for clinical practice. By allowing earlier management of undernutrition, body composition evaluation can contribute to reducing malnutrition-induced morbidity and mortality, improving the quality of life and, as a consequence, increasing the medico-economic benefits (fig. 1). The latter needs to be demonstrated. Moreover, based on a more scientific approach, i.e. allowing for printing reports, objective initial assessment and follow-up of nutritional status, and the adjustment of drug doses, body composition evaluation would contribute to a better recognition of the activities related to nutritional evaluation and care by the medical community, health care facilities, and health authorities (fig. 2).

\section{Conclusion}

Screening of undernutrition is insufficient to allow for optimal nutrition care. This is in part due to the lack of sensitivity of BMI and weight loss for detecting FFM loss in patients with chronic diseases. Methods of body composition evaluation allow a quantitative measurement of FFM changes during the course of disease and could be used to detect FFM loss in the setting of an objective, systematic, and early undernutrition screening. FFM loss is closely related to impaired clinical outcomes, survival, and quality of life, as well as increased therapy toxicity in cancer patients. Thus, body composition evaluation should be integrated into clinical practice for the initial assessment, sequential follow-up of nutritional status, and the tailoring of nutritional and disease-specific therapies. Body composition evaluation could contribute to strengthening the role and credibility of nutrition in the global medical management, reducing the negative impact of malnutrition on the clinical outcome and quality of life, thereby increasing the overall medico-economic benefits.

\section{Acknowledgements}

R. Thibault and C. Pichard are supported by research grants from the public foundation Nutrition 2000 Plus.

\section{Disclosure Statement}

Ronan Thibault and Claude Pichard declare no conflict of interest.

Ann Nutr Metab 2012;60:6-16 


\section{References}

1 Pirlich M, Schutz T, Norman K, Gastell S, Lübke HJ, Bischoff SC, Bolder U, Frieling T, Güldenzoph H, Hahn K, Jauch KW, Schindler K, Stein J, Volkert D, Weimann A, Werner H, Wolf C, Zürcher G, Bauer P, Lochs $\mathrm{H}$ : The German hospital malnutrition study. Clin Nutr 2006;25:563-572.

-2 Amaral TF, Matos LC, Tavares MM, Subtil A, Martins R, Nazaré M, Sousa Pereira N: The economic impact of disease-related malnutrition at hospital admission. Clin Nutr 2007;26:778-784

- 3 Pichard C, Kyle UG, Morabia A, Perrier A, Vermeulen B, Unger P: Nutritional assessment: lean body mass depletion at hospital admission is associated with increased length of stay. Am J Clin Nutr 2004;79:613618.

-4 Capuano G, Gentile PC, Bianciardi F, Tosti M, Palladino A, Di Palma M: Prevalence and influence of malnutrition on quality of life and performance status in patients with locally advanced head and neck cancer before treatment. Support Care Cancer 2010;18: 433-437.

-5 Prado CM, Lieffers JR, McCargar LJ, Reiman T, Sawyer MB, Martin L, Baracos VE: Prevalence and clinical implications of sarcopenic obesity in patients with solid tumours of the respiratory and gastrointestinal tracts: a population-based study. Lancet Oncol 2008; 9:629-635.

-6 Tan BHL, Birdsell LA, Martin L, Baracos VE, Fearon KC: Sarcopenia in an overweight or obese patient is an adverse prognostic factor in pancreatic cancer. Clin Cancer Res 2009; 15:6973-6979.

-7 Baracos VE, Reiman T, Mourtzakis M, Gioulbasanis I, Antoun S: Body composition in patients with non-small cell lung cancer: a contemporary view of cancer cachexia with the use of computed tomography image analysis. Am J Clin Nutr 2010;91(suppl): 1133S-1137S

$\checkmark 8$ Antoun S, Baracos VE, Birdsell L, Escudier B, Sawyer MB: Low body mass index and sarcopenia associated with dose-limiting toxicity of sorafenib in patients with renal cell carcinoma. Ann Oncol 2010;21:1594-1598

-9 Prado CM, Baracos VE, McCargar LJ, Mourtzakis M, Mulder KE, Reiman T, Butts CA, Scarfe AG, Sawyer MB: Body composition as an independent determinant of 5-fluorouracil-based chemotherapy toxicity. Clin Cancer Res 2007;13:3264-3268.

10 Prado CM, Baracos VE, McCargar LJ, Reiman T, Mourtzakis M, Tonkin K, Mackey JR, Koski S, Pituskin E, Sawyer MB: Sarcopenia as a determinant of chemotherapy toxicity and time to tumor progression in metastatic breast cancer patients receiving capecitabine treatment. Clin Cancer Res 2009;15:29202926.
1 Hofhuis JG, Spronk PE, van Stel HF, Schrijvers GJ, Rommes JH, Bakker J: The impact of critical illness on perceived health-related quality of life during ICU treatment, hospital stay, and after hospital discharge: a longterm follow-up study. Chest 2008;133:377385.

12 Guest JF, Panca M, Baeyens JP, de Man F, Ljungqvist $\mathrm{O}$, Pichard C, Wait S, Wilson L: Health economic impact of managing patients following a community-based diagnosis of malnutrition in the UK. Clin Nutr 2011; 30:422-429.

13 Kyle UG, Morabia A, Slosman DO, Mensi N, Unger P, Pichard C: Contribution of body composition to nutritional assessment at hospital admission in 995 patients: a controlled population study. Br J Nutr 2001;86: 725-731.

14 Kondrup J, Allison SP, Elia M; Vellas B, Plauth M: Educational and Clinical Practice Committee, European Society of Parenteral and Enteral Nutrition (ESPEN): ESPEN guidelines for nutrition screening 2002. Clin Nutr 2003;22:415-421.

15 Haute Autorité de Santé: IPAQSS: informations. 2010. http://www.has-sante.fr/portail/ jcms/c 970427/ipaqss-informations.

16 World Health Organization: Obesity and overweight: fact sheet No. 311. 2011. http:// www.who.int/mediacentre/factsheets/fs311/ en/index.html.

17 Thibault R, Chikhi M, Clerc A, Darmon P, Chopard P, Picard-Kossovsky M, Genton L, Pichard C: Assessment of food intake in hospitalised patients: a 10 year-comparative study of a prospective hospital survey. Clin Nutr 2011;30:289-296.

18 Stenholm S, Harris TB, Rantanen T, Visser M, Kritchevsky SB, Ferrucci L: Sarcopenic obesity: definition, cause and consequences. Curr Opin Clin Nutr Metab Care 2008;11: 693-700.

19 Pichard C, Kyle UG: Body composition measurements during wasting diseases. Curr Opin Clin Nutr Metab Care 1998;1:357-361.

20 Wang ZM, Pierson RN Jr, Heymsfield SB: The five-level model: a new approach to organizing body-composition research. Am J Clin Nutr 1992;56:19-28.

21 Schols AM, Broekhuizen R, Weling-Scheepers CA, Wouters EF: Body composition and mortality in chronic obstructive pulmonary disease. Am J Clin Nutr 2005;82:53-59.

22 Slinde F, Gronberg A, Engstrom CP, Rossander-Hulthen L, Larsson S: Body composition by bioelectrical impedance predicts mortality in chronic obstructive pulmonary disease patients. Respir Med 2005;99:10041009.
23 Vestbo J, Prescott E, Almdal T, Dahl M, Nordestgaard BG, Andersen T, Sorensen TI, Lange P: Body mass, fat-free body mass, and prognosis in patients with chronic obstructive pulmonary disease from a random population sample: findings from the Copenhagen City Heart Study. Am J Respir Crit Care Med 2006;173:79-83.

24 Segall L, Mardare NG, Ungureanu S, Busuioc M, Nistor I, Enache R, Marian S, Covic A: Nutritional status evaluation and survival in haemodialysis patients in one centre from Romania. Nephrol Dial Transplant 2009;24: 2536-2540.

25 Beddhu S, Pappas LM, Ramkumar N, Samore M: Effects of body size and body composition on survival in hemodialysis patients. J Am Soc Nephrol 2003;14:2366-2372.

-26 Fürstenberg A, Davenport A: Assessment of body composition in peritoneal dialysis patients using bioelectrical impedance and dual-energy X-ray absorptiometry. Am J Nephrol 2011;33:150-156.

27 Futter JE, Cleland JG, Clark AL: Body mass indices and outcome in patients with chronic heart failure. Eur J Heart Fail 2011;13:207213.

28 Marin B, Desport JC, Kajeu P, Jesus P, Nicolaud B, Nicol M, Preux PM, Couratier P: Alteration of nutritional status at diagnosis is a prognostic factor for survival of amyotrophic lateral sclerosis patients. J Neurol Neurosurg Psychiatry 2011;82:628-634.

-29 Janiszewski PM, Oeffinger KC, Church TS, Dunn AL, Eshelman DA, Victor RG, Brooks S, Turoff AJ, Sinclair E, Murray JC, Bashore L, Ross R: Abdominal obesity, liver fat, and muscle composition in survivors of childhood acute lymphoblastic leukemia. J Clin Endocrinol Metab 2007;92:3816-3821.

30 Wagner D, Adunka C, Kniepeiss D, Jakoby E, Schaffellner S, Kandlbauer M, Fahrleitner-Pammer A, Roller RE, Kornprat P, Müller H, Iberer F, Tscheliessnigg KH: Serum albumin, subjective global assessment, body mass index and the bioimpedance analysis in the assessment of malnutrition in patients up to 15 years after liver transplantation. Clin Transplant 2011;25:E396-E400.

- 31 Kimyagarov S, Klid R, Levenkrohn S, Fleissig Y, Kopel B, Arad M, Adunsky A: Body mass index (BMI), body composition and mortality of nursing home elderly residents. Arch Gerontol Geriatr 2010;51:227-230.

- 32 Buffa R, Mereu RM, Putzu PF, Floris G, Marini E: Bioelectrical impedance vector analysis detects low body cell mass and dehydration in patients with Alzheimer's disease. J Nutr Health Aging 2010;14:823-827.

- 33 Schols AM, Wouters EF, Soeters PB, Westerterp KR: Body composition by bioelectricalimpedance analysis compared with deuterium dilution and skinfold anthropometry in patients with chronic obstructive pulmonary disease. Am J Clin Nutr 1991;53:421-424. 
- 34 Thibault R, Le Gallic E, Picard-Kossovsky M, Darmaun D, Chambellan A: Assessment of nutritional status and body composition in patients with COPD: comparison of several methods (in French). Rev Mal Respir 2010;27:693-702.

- 35 Kyle UG, Janssens JP, Rochat T, Raguso CA, Pichard C: Body composition in patients with chronic hypercapnic respiratory failure. Respir Med 2006;100:244-252.

- 36 Rieken R, van Goudoever JB, Schierbeek H, Willemsen SP, Calis EA, Tibboel D, Evenhuis HM, Penning C: Measuring body composition and energy expenditure in children with severe neurologic impairment and intellectual disability. Am J Clin Nutr 2011;94:759766

37 Avram MM, Fein PA, Borawski C, Chattopadhyay J, Matza B: Extracellular mass/body cell mass ratio is an independent predictor of survival in peritoneal dialysis patients. Kidney Int Suppl 2010;117:S37-S40.

- 38 Frisancho AR: New norms of upper limb fat and muscle areas for assessment of nutritional status. Am J Clin Nutr 1981;34:2540-2545.

39 Caregaro L, Alberino F, Amodio P, Merkel C, Bolognesi M, Angeli P, Gatta A: Malnutrition in alcoholic and virus-related cirrhosis. Am J Clin Nutr 1996;63:602-609.

-40 Alberino F, Gatta A, Amodio P, Merkel C, Di Pascoli L, Boffo G, Caregaro L: Nutrition and survival in patients with liver cirrhosis. Nutrition 2001;17:445-450.

-41 Liu E, Spiegelman D, Semu H, Hawkins C, Chalamilla G, Aveika A, Nyamsangia S, Mehta S, Mtasiwa D, Fawzi W: Nutritional status and mortality among HIV-infected patients receiving antiretroviral therapy in Tanzania. J Infect Dis 2011;204:282-290.

42 Soler-Cataluna JJ, Sanchez-Sanchez L, Martinez-Garcia MA, Sanchez PR, Salcedo E, Navarro M: Mid-arm muscle area is a better predictor of mortality than body mass index in COPD. Chest 2005;128:2108-2115.

43 Marquis K, Debigaré R, Lacasse Y, LeBlanc P, Jobin J, Carrier G, Maltais F: Midthigh muscle cross-sectional area is a better predictor of mortality than body mass index in patients with chronic obstructive pulmonary disease. Am J Respir Crit Care Med 2002;15; 166:809-813.

-44 Kyle UG, Pirlich M, Lochs H, Schuetz T, Pichard C: Increased length of hospital stay in underweight and overweight patients at hospital admission: a controlled population study. Clin Nutr 2005;24:133-142.

-45 Kyle UG, Bosaeus I, De Lorenzo AD, Deurenberg P, Elia M, Gómez JM, Heitmann BL, Kent-Smith L, Melchior JC, Pirlich M, Scharfetter H, Schols AM, Pichard C, Composition of the ESPEN Working Group. Bioelectrical impedance analysis. 1. Review of principles and methods. Clin Nutr 2004;23: 1226-1243.
46 Santarpia L, Marra M, Montagnese C, Alfonsi L, Pasanisi F, Contaldo F: Prognostic significance of bioelectrical impedance phase angle in advanced cancer: preliminary observations. Nutrition 2009;25:930-931.

-47 Gupta D, Lammersfeld CA, Vashi PG, King J, Dahlk SL, Grutsch JF, Lis CG: Bioelectrical impedance phase angle in clinical practice: implications for prognosis in stage IIIB and IV non-small cell lung cancer. BMC Cancer 2009;9:37.

48 Gupta D, Lis CG, Dahlk SL, Vashi PG, Grutsch JF, Lammersfeld CA: Bioelectrical impedance phase angle as a prognostic indicator in advanced pancreatic cancer. $\mathrm{Br} \mathrm{J}$ Nutr 2004;92:957-962.

-49 Gupta D, Lammersfeld CA, Burrows JL, Dahlk SL, Vashi PG, Grutsch JF, Hoffman S, Lis CG: Bioelectrical impedance phase angle in clinical practice: implications for prognosis in advanced colorectal cancer. Am J Clin Nutr 2004;80:1634-1638.

-50 Paiva SI, Borges LR, Halpern-Silveira D, Assunção MC, Barros AJ, Gonzalez MC: Standardized phase angle from bioelectrical impedance analysis as prognostic factor for survival in patients with cancer. Support Care Cancer 2010;19:187-192.

-51 Schwenk A, Beisenherz A, Römer K, Kremer G, Salzberger B, Elia M: Phase angle from bioelectrical impedance analysis remains an independent predictive marker in HIV-infected patients in the era of highly active antiretroviral treatment. Am J Clin Nutr 2000; 72:496-501

52 Desport JC, Marin B, Funalot B, Preux PM, Couratier P: Phase angle is a prognostic factor for survival in amyotrophic lateral sclerosis. Amyotroph Lateral Scler 2008;9:273278.

53 Wirth R, Volkert D, Rösler A, Sieber CC, Bauer JM: Bioelectric impedance phase angle is associated with hospital mortality of geriatric patients. Arch Gerontol Geriatr 2010;51:290-294.

- 54 Mushnick R, Fein PA, Mittman N, Goel N, Chattopadhyay J, Avram MM: Relationship of bioelectrical impedance parameters to nutrition and survival in peritoneal dialysis patients. Kidney Int Suppl 2003;87:S53-S56.

55 Selberg O, Selberg D: Norms and correlates of bioimpedance phase angle in healthy human subjects, hospitalized patients, and patients with liver cirrhosis. Eur J Appl Physiol 2002;86:509-516.

-56 Shah S, Whalen C, Kotler DP, Mayanja H, Namale A, Melikian G, Mugerwa R, Semba RD: Severity of human immunodeficiency virus infection is associated with decreased phase angle, fat mass and body cell mass in adults with pulmonary tuberculosis infection in Uganda. J Nutr 2001;131:2843-2847.

57 Barbosa-Silva MC, Barros AJ: Bioelectric impedance and individual characteristics as prognostic factors for post-operative complications. Clin Nutr 2005;24:830-838.
58 Durnin JV, Womersley J: Body fat assessed from total body density and its estimation from skinfold thickness: measurements on 481 men and women aged from 16 to 72 years. Br J Nutr 1974;32:77-97.

59 Hill GL: Body composition research: implications for the practice of clinical nutrition. JPEN J Parenter Enter Nutr 1992;16:197-218.

60 Pierson RN Jr, Wang J, Thornton JC, Van Itallie TB, Colt EW: Body potassium by fourpi $40 \mathrm{~K}$ counting: an anthropometric correction. Am J Physiol 1984;246:F234-F239.

61 Sohlström A, Forsum E: Changes in total body fat during the human reproductive cycle as assessed by magnetic resonance imaging, body water dilution, and skinfold thickness: a comparison of methods. Am J Clin Nutr 1997;66:1315-1322.

62 Leonard CM, Roza MA, Barr RD, Webber CE: Reproducibility of DXA measurements of bone mineral density and body composition in children. Pediatr Radiol 2009;39:148154 .

63 Genton L, Karsegard VL, Zawadynski S, Kyle UG, Pichard C, Golay A, Hans DB: Comparison of body weight and composition measured by two different dual energy X-ray absorptiometry devices and three acquisition modes in obese women. Clin Nutr 2006;25: 428-437.

64 Jaffrin MY: Body composition determination by bioimpedance: an update. Curr Opin Clin Nutr Metab Care 2009;12:482-486.

65 Kyle UG, Pichard C, Rochat T, Slosman DO, Fitting JW, Thiebaud D: New bioelectrical impedance formula for patients with respiratory insufficiency: comparison to dual-energy X-ray absorptiometry. Eur Respir J 1998; 12:960-966.

66 Kyle UG, Bosaeus I, De Lorenzo AD, Deurenberg P, Elia M, Manuel Gómez J, Lilienthal Heitmann B, Kent-Smith L, Melchior JC, Pirlich M, Scharfetter H, Schols AMWJ, Pichard C, ESPEN: Bioelectrical impedance analysis. 2. Utilization in clinical practice. Clin Nutr 2004;23:1430-1453.

67 Mourtzakis M, Prado CM, Lieffers JR, Reiman T, McCargar LJ, Baracos VE: A practical and precise approach to quantification of body composition in cancer patients using computed tomography images acquired during routine care. Appl Physiol Nutr Metab 2008;33:997-1006.

68 Bolton CE, Ionescu A A, Shiels KM, Pettit RJ, Edwards PH, Stone MD, Nixon LS, Evans WD, Griffiths TL, Shale DJ: Associated loss of fat-free mass and bone mineral density in chronic obstructive pulmonary disease. Am J Respir Crit Care Med 2004;170:1286-1293.

-69 Kyle UG, Genton L, Karsegard L, Slosman DO, Pichard C: Single prediction equation for bioelectrical impedance analysis in adults aged 20-94 years. Nutrition 2001;17: 248-253. 
-70 Kyle UG, Genton L, Slosman DO, Pichard C: Fat-free and fat mass percentiles in 5,225 healthy subjects aged 15 to 98 years. Nutrition 2001; 17(7-8):534-541.

71 Kotler DP, Burastero S, Wang J, Pierson RN Jr: Prediction of body cell mass, fat-free mass, and total body water with bioelectrical impedance analysis: effects of race, sex, and disease. Am J Clin Nutr 1996;64:489S-497S.

72 Kyle UG, Genton L, Mentha G, Nicod L, Slosman DO, Pichard C: Reliable bioelectrical impedance analysis estimate of fat-free mass in liver, lung, and heart transplant patients. JPEN J Parenter Enteral Nutr 2001;25:45-51.

73 Mattar L, Godart N, Melchior JC, Falissard B, Kolta S, Ringuenet D, Vindreau C, Nordon C, Blanchet C, Pichard C: Underweight patients with anorexia nervosa: comparison of bioelectrical impedance analysis using five equations to dual X-ray absorptiometry. Clin Nutr 2011, E-pub ahead of print.

74 Genton L, Karsegard VL, Kyle UG, Hans DB, Michel JP, Pichard C: Comparison of four bioelectrical impedance analysis formulas in healthy elderly subjects. Gerontology 2001; 47:315-323.

75 Robert S, Zarowitz BJ, Hyzy R, Eichenhorn M, Peterson EL, Popovich J Jr: Bioelectrical impedance assessment of nutritional status in critically ill patients. Am J Clin Nutr 1993; 57:840-844.

76 Pichard C, Kyle UG, Slosman DO, Penalosa B: Energy expenditure in anorexia nervosa: can fat-free mass as measured by bioelectrical impedance predict energy expenditure in hospitalized patients? Clin Nutr 1996;15: 109-114.

-77 Kreymann KG, Berger MM, Deutz NE, Hiesmayr M, Jolliet P, Kazandjiev G, Nitenberg G, van den Berghe G, Wernerman J, DGEM (German Society for Nutritional Medicine), Ebner C, Hartl W, Heymann C, Spies C, ESPEN: ESPEN guidelines on enteral nutrition: intensive care. Clin Nutr 2006;25:210-223.

78 Singer P, Berger MM, van den Berghe G, Biolo G, Calder P, Forbes A, Griffiths R, Kreyman G, Leverve X, Pichard C, ESPEN: ESPEN guidelines on parenteral nutrition: intensive care. Clin Nutr 2009;28:387-400.

79 Magnuson B, Peppard A, Auer Flomenhoft D: Hypocaloric considerations in patients with potentially hypometabolic disease states. Nutr Clin Pract 2011;26:253-260.
80 Rigaud D, Boulier A, Tallonneau I, Brindisi MC, Rozen R: Body fluid retention and body weight change in anorexia nervosa patients during refeeding. Clin Nutr 2010;29:749755.

81 Kyle UG, Chalandon Y, Miralbell R, Karsegard VL, Hans D, Trombetti A, Rizzoli R, Helg C, Pichard C: Longitudinal follow-up of body composition in hematopoietic stem cell transplant patients. Bone Marrow Transplant 2005;35:1171-1177.

82 Pison CM, Cano NJ, Cherion C, Caron F, Court-Fortune I, Antonini M, GonzalezBermejo J, Meziane L, Molano LC, Janssens JP, Costes F, Wuyam B, Similowski T, Melloni B, Hayot M, Augustin J, Tardif C, Lejeune H, Roth H, Pichard C, the IRAD Investigators: Multimodal nutritional rehabilitation improves clinical outcomes of malnourished patients with chronic respiratory failure: a controlled randomised trial. Tho$\operatorname{rax} 2011 ; 66: 953-960$.

83 Pichard C, Kyle U, Chevrolet JC, Jolliet P, Slosman D, Mensi N, Temler E, Ricou B: Lack of effects of recombinant growth hormone on muscle function in patients requiring prolonged mechanical ventilation: a prospective, randomized, controlled study. Crit Care Med 1996;24:403-413.

84 Pichard C, Kyle UG, Jolliet P, Slosman DO, Rochat T, Nicod L, Romand J, Mensi N, Chevrolet JC: Treatment of cachexia with recombinant growth hormone in a patient before lung transplantation: a case report. Crit Care Med 1999;27:1639-1642.

85 Leslie WD, Miller N, Rogala L, Bernstein $\mathrm{CN}$ : Body mass and composition affect bone density in recently diagnosed inflammatory bowel disease: the Manitoba IBD Cohort Study. Inflamm Bowel Dis 2009;15:39-46.

-86 van der Meij BS, Langius JA, Smit EF, Spreeuwenberg MD, von Blomberg BM, Heijboer AC, Paul MA, van Leeuwen PA Oral nutritional supplements containing (n3) polyunsaturated fatty acids affect the nutritional status of patients with stage III nonsmall cell lung cancer during multimodality treatment. J Nutr 2010;140:1774-1780.
87 Ryan AM, Reynolds JV, Healy L, Byrne M, Moore J, Brannelly N, McHugh A, McCormack D, Flood P: Enteral nutrition enriched with eicosapentaenoic acid (EPA) preserves lean body mass following esophageal cancer surgery: results of a double-blinded randomized controlled trial. Ann Surg 2009;249: 355-363.

>88 Ndekha MJ, Oosterhout JJ, Zijlstra EE, Manary M, Saloojee H, Manary MJ: Supplementary feeding with either ready-to-use fortified spread or corn-soy blend in wasted adults starting antiretroviral therapy in $\mathrm{Ma}$ lawi: randomised, investigator blinded, controlled trial. BMJ 2009;338:b1867-b1875.

89 Ha L, Hauge T, Iversen PO: Body composition in older acute stroke patients after treatment with individualized, nutritional supplementation while in hospital. BMC Geriatrics 2010;10:75.

-90 Genton L, Karsegard VL, Chevalley T, Kossovsky MP, Darmon P, Pichard C: Body composition changes over 9 years in healthy elderly subjects and impact of physical activity. Clin Nutr 2011;30:436-442.

$\checkmark 91$ Reid CL, Murgatroyd PR, Wright A, Menon DK: Quantification of lean and fat tissue repletion following critical illness: a case report. Crit Care 2008;12:R79.

92 Antoun S, Birdsel Ll, Sawyer MB, Venner P, Escudier B, Baracos VE: Association of skeletal muscle wasting with treatment with sorafenib in patients with advanced renal cell carcinoma: results from a placebo-controlled study. J Clin Oncol 2010;28:10541060.

$\$ 93$ Prado CM, Antoun S, Sawyer MB, Baracos VE: Two faces of drug therapy in cancer: drug-related lean tissue loss and its adverse consequences to survival and toxicity. Curr Opin Clin Nutr Metab Care 2011;14:250254.

94 Schutz Y, Kyle UG, Pichard C: Fat-free mass index and fat mass index percentiles in Caucasians aged 18-98 y. Int J Obes 2002;26: 953-960.

$\checkmark 5$ Kyle UG, Schutz Y, Dupertuis YM, Pichard C: Body composition interpretation: contributions of the fat-free mass index and the body fat mass index. Nutrition 2003;19:597604.

>96 Kyle UG, Piccoli A, Pichard C: Body composition measurements: interpretation finally made easy for clinical use. Curr Opin Clin Nutr Metab Care 2003;6:387-393. 